1769. Dinesen. Personalized

https://doi.org/10.30953/tmt.v2.18

Page 1 of 38

\title{
Personalized Telehealth in the Future: A Global Research Agenda
}

Birthe Dinesen, ${ }^{1}$ Brandie Nonnecke, ${ }^{2}$ David Lindeman, ${ }^{2}$ Egon Toft, ${ }^{3}$ Kristian Kidholm, ${ }^{4}$ Kamal Jethwani, ${ }^{5}$ Heather M Young, ${ }^{6}$ Helle Spindler, ${ }^{7}$ Claus Ugilt Oestergaard, ${ }^{1,8}$ Jeffrey A Southard, ${ }^{9}$ Mario Gutierrez, ${ }^{10}$ Nick Anderson, ${ }^{11}$ Nancy M Albert, ${ }^{12}$ Jay J Han, ${ }^{13}$ Thomas Nesbitt. 2,13

Editor's note: This article was originally published in the Journal of Medical Internet Research. The authors provide an extensively referenced global overview of the state of telehealth services and benefits, fundamental principles to advance the status quo, and a framework for telehealth research for personalized care, treatment, and prevention. It has been edited for a concise presentation of information with recommendations.

Telecommunication technologies have been used to bring healthcare expertise to the point of care since the 19th century. In 1878, The Lancet reported the use of the telephone to reduce unnecessary physician visits and, in 1910, a tele-stethoscope had already been described. ${ }^{1}$ During the mid-20th century, NASA (National Aeronautics and Space Administration) used remote monitoring systems to measure astronauts' physiological functions. The Space Technology Applied to Rural Papago Advanced Health Care project further developed this field with the Papago Indians in the southwestern U.S. ${ }^{2}$ However, the greatest strides in remote monitoring technologies for telehealth have occurred over the last 10 years, with a growing evidence base showing their effectiveness in the management of chronic disease. ${ }^{3-5}$

The importance of telehealth for delivering care over distance has become increasingly relevant as the world's healthcare needs are overwhelmed by an increase in global chronic disease, which now exceeds communicable disease as the leading cause of death worldwide. In the U.S., more than $70 \%$ of deaths are associated with chronic diseases, and approximately $75 \%$ of annual healthcare expenses are used on persons with chronic conditions, ${ }^{6,7}$ a problem that is increasing as the prevalence of chronic diseases grows with aging. In the EU, it is estimated that chronic illness is a factor in 
1769. Dinesen. Personalized

https://doi.org/10.30953/tmt.v2.18

Page 2 of 38

$87 \%$ of all deaths. ${ }^{8}$

Some telehealth models of care show benefits for patients with chronic disease that incorporate patients and family members into the care team, ${ }^{9}$ whereas others have not been able to demonstrate significant improvements. ${ }^{10}$ These models, which frequently involve remote patient monitoring (RPM), show promise in getting and maintaining patients to achieve their healthcare goal and, in some cases, lowering the incidence of avoidable hospitalizations and rehospitalizations for patients with chronic

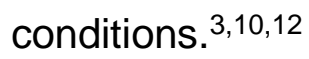

In the U.S. and the EU, telehealth technologies have also been effective in small-scale studies of patients with chronic diseases; nevertheless, adoption of telehealth solutions remains limited. $5,13,14$ There are several obstacles to achieving widespread adoption of telehealth: acceptance technology by patients and clinicians, sustainable reimbursement systems; interoperability between electronic patient record systems; and technological capacity in smaller hospitals, clinics, and in the home.

\section{Telehealth Today: Benefit and Biases}

In 2008, a meta-analysis of home monitoring studies globally found it was a costeffective alternative in 21 of 23 studies, most which focused on chronic disease care. ${ }^{15}$ The main benefits derived from RPM programs were decreased hospital utilization, improved patient compliance with treatment plans, improved patient satisfaction with health services, and improved quality of life.

Multiple studies report savings associated with application of telehealth for home monitoring when applied to heart failure patients. Recent studies that compared telehealth to traditional outpatient care recorded savings estimates from $17 \%$ to $75 \%$. $^{16-}$ 22 Similarly, a review of telehealth studies among patients with chronic obstructive pulmonary disease (COPD), heart failure, and stroke reported reductions in hospital admissions/readmissions, length of hospital stay, emergency department visits, and often a decrease in mortality. ${ }^{23}$ 
1769. Dinesen. Personalized

https://doi.org/10.30953/tmt.v2.18

Page 3 of 38

Although benefits of telehealth were cited in these studies, Wootton ${ }^{5}$ identified a publication bias in telehealth studies of chronic disease management, with 108 of 110 articles reporting positive effects. Telehealth studies were characterized by a short duration, averaging 6 months, and there were few studies of cost-effectiveness. Wootton concluded that the evidence base of telehealth and chronic disease management was both contradictory and weak. ${ }^{5}$

A review of the cost-effectiveness of telehealth ${ }^{24}$ concludes that economic tools for evaluation are increasingly used, but better reporting of methodologies and findings is required. The review also concluded there was no convincing evidence to show that telehealth was more cost-effective than conventional healthcare. ${ }^{5}$

In the UK, a large telehealth project, the Whole System Demonstrator (WSD) project, was carried out with 3230 patients between 2008 and 2009, including those with heart, lung, and diabetes diseases using a cluster randomized design. During a 12-month observation, researchers found reductions in mortality and hospital admissions. ${ }^{25}$ The effects on health-related quality of life were shown not to be significant. ${ }^{26}$ An economic analysis of the WSD concluded that telehealth was not cost-effective when used as an add-on to standard care and treatment for patients. ${ }^{27}$

In addition, a longitudinal case study of the organizational effects of the WSD showed that the randomized research design impeded organizational learning among trial sites and the full organizational benefit of WSD was not achieved. ${ }^{28}$ In the WSD, qualitative interviews were carried out with patients who declined to participate in the study. Among this group, $36.7 \%$ chose not to participate in the study following a home visit in which they had been informed about the study. Their primary concerns were threats to identity, independence, and self-care; requirements of technical competence and ability to operate equipment; and experiences of disruption of health and social care services. ${ }^{29}$ The implication is that there is a bias in telehealth studies, and studied tend to consist of people already positively disposed to telehealth measures. 
In a systematic review focusing on patients' acceptance of telehealth technologies, focusing on patient factors alone was not sufficient for understanding the degree of patients' interest (or lack of interest) in using telehealth technologies. ${ }^{30}$ Future research should identify factors that promote telehealth acceptance, such as human-technology interaction, organization of the healthcare system, and social factors. We do not claim that telehealth should be held to a higher evaluation standard than what has been applied to traditional modes of care. However, investigating additional features that affect the success of telehealth utilization will enable more informed development of future telehealth implementations.

\section{Telehealth Challenges}

Healthcare financing models exist in many industrialized nations. In the U.S. in 2011, a national quality strategy for establishing aims and priorities for quality improvement, known as "the Triple Aims," 31 included improving the overall quality of healthcare, better population and community health outcomes, and reducing the overall cost of care. In the U.S. and the EU, it is anticipated that technology will play a pivotal role in achieving these goals.

Nevertheless, even with governmental support and a growing evidence base demonstrating the benefit of healthcare financing models of care that included telehealth, there remain many challenges facing the establishment and sustainability of effective telehealth programs. Financial sustainability of telehealth models of care has been one of the main challenges, particularly in the U.S., where-despite the intent of the Affordable Care Act-reimbursement has been and continues to focus more on paying for care processes that occur within healthcare facilities rather than care processes that affect patient outcomes. Although reimbursement for telehealth increased in the U.S., payers such as Medicare do not recognize the home as a reimbursable originating site of care.

In settings with capitated reimbursement, such as the U.S. Veterans Administration, 
1769. Dinesen. Personalized

https://doi.org/10.30953/tmt.v2.18

Page 5 of 38

telehealth solutions (RPM and home-based chronic disease management) has had remarkable success. ${ }^{3}$ Among 17,025 adults, researchers found a $25 \%$ reduction in hospital length of stay, a $19 \%$ reduction in hospital admissions, and a mean satisfaction score rating of $86 \%$, all at a cost of U.S. $\$ 1600$ per patient per annum. ${ }^{3}$

There are additional challenges beyond reimbursement to bring telehealth models to scale across different health systems and independent practitioners in the U.S. and the EU. Most successful telehealth models require an extensive care team, including disease management nurses and other personnel. Independent practitioners may not be able to employ care teams and would potentially need to rely on an intensive service model, such as visiting nurses for home healthcare. Effective implementation of telehealth often requires receiving and processing data from various devices, which need to be analyzed and translated into actionable clinical information for physicians and other healthcare providers.

To put it simply, if data from RPM and other telehealth technologies are to be used for clinical decision making, the clinician must be assured that physiological and activity data are accurate. Initiatives such as the Personal Connected Health Alliance are intended to assure this. As the use of RPM and telehealth becomes standardized and ubiquitous, and as health data are collected and stored in standard formats, there are considerable opportunities to apply predictive analytics.

Ideally, clinicians should have easily interpretable dashboards identifying the daily health statuses for all their chronic disease patients. Some organizations have already begun developing and using chronic disease dashboards for conditions such as diabetes. ${ }^{32}$ There are also opportunities to adapt off-the-shelf technologies, such as mobile phones and gaming systems, to serve as tools in remote chronic disease management. Ultimately, for technology-enabled chronic disease models to be adopted on a large scale, more research is needed to determine healthcare professionals' and patients' preferences for technologies, care models, and methods to assure accurate data. 
1769. Dinesen. Personalized

https://doi.org/10.30953/tmt.v2.18

Page 6 of 38

As new technology solutions, such as sensors, mobile devices, and self-tracking technologies, become prevalent, organizations will increase use and reimbursement of technology-driven healthcare services. As technology-driven healthcare services grow, this will require development of efficient business models and cases for telehealth stakeholders.

\section{Policy Challenges Within Telehealth}

Telehealth policies among U.S. states, U.S. federal agencies, and EU countries are outdated and woefully inadequate to support widespread telehealth adoption and growth. In 2015, the California-based Center for Connected Health Policy (CCHP) undertook a comprehensive analysis of the laws, regulations, and related administrative policies of the 50 states in the U.S. as well as the federal U.S. policy. ${ }^{33}$ Given that each state can define its own policies for its Medicaid Program, a wide range of definitions and reimbursement policies for telehealth care were found, with no two states being alike. Based on the CCHP review, there are several critical policy issues that require attention: (1) defining telehealth care, (2) setting reimbursement policies, (3) licensing and jurisdictional issues, and (4) cost-benefit analysis of telehealth systems. It is hoped that refinements in these state policy initiatives will enable the achievement of the following three goals:

1 Creation of parity for telehealth with other modes of healthcare delivery;

2 Active promotion of telehealth as a tool to advance stakeholder goals regarding health status, equity of access, greater efficiency in care delivery, and health systems improvements; and

3 Creation of opportunities and flexibility for telehealth to be used in new models of care and systems improvements.

The U.S. federal policy governing the use of telehealth in the Medicare program is also limited. Reimbursement is limited to certain billing codes and only for live video care. In addition, these services are limited to beneficiaries residing in strictly defined rural communities. 
1769. Dinesen. Personalized

https://doi.org/10.30953/tmt.v2.18

Page 7 of 38

Analysis of the eHealth policy initiatives within 27 EU Member States influenced the development of an eHealth roadmap that reflects national, regional, and local conditions beyond technical imperatives to include personalized telehealth solutions. ${ }^{34}$

Commonalities among U.S. and EU telehealth policies exist at national and regional levels resulting in generally uniform policy solutions; however, locally there tends to be a lack of personalized telehealth solutions.

\section{Definitions and Nomenclature}

In a 2014 study, ${ }^{35} 26$ U.S. federal agencies were surveyed with seven distinctly unique working definitions of "telehealth" identified. The study concluded that a common nomenclature for defining telehealth may benefit efforts to advance the use of this technology so that it can address the changing nature of healthcare and the emerging demands for services as a result of healthcare reforms ${ }^{35} \mathrm{EU}$ telehealth definitions and applications reveal similarly wide variation of terms and restrictions in use. ${ }^{36}$ Internationally, there is neither a common understanding of the various forms of technology-enabled healthcare nor precision in the description of the range of healthrelated activities and services covered via telehealth.

\section{Reimbursement}

In the U.S. and EU, reimbursement of telehealth-delivered care and specific reimbursement requirements remain a major challenge. A legal definition of telehealth may relate directly to services reimbursed by public and private payers and the conditions for this reimbursement. It would be beneficial if reimbursement policies, in addition to including live video, were consistent within and between countries and included asynchronous "store-and-forward" and remote monitoring.

Policies should also be sufficiently flexible to create parity and not be restricted by artificial barriers such as geographic limitations (as is the case with Medicare in the U.S.). Technology-enabled healthcare should be a virtual modality, not a distinctly separate service requiring unique billing codes. The impact of telehealth-enabled 
1769. Dinesen. Personalized

https://doi.org/10.30953/tmt.v2.18

Page 8 of 38

healthcare will become more of a reality in the U.S. as health systems shift from fee-forservice to more value-based capitated systems under healthcare reform. In the EU and other countries with nationalized healthcare, opportunities for incorporating telehealth practices in innovative reimbursement schemes are being advanced within different healthcare systems.

\section{Licensing and Jurisdictional Issues}

The scaling of telehealth, particularly in the U.S., is limited by professional licensing issues and competition among professionals. The ability to provide high-quality virtual synchronous and asynchronous healthcare and patient monitoring has created unprecedented opportunities for dramatically expanding access to quality care for the underserved and simultaneously increasing the efficiency and lowering the costs of care. ${ }^{37}$ Services can now be effectively provided across the street and around the planet if there is access to high-speed Internet. However, the definition and interpretation of the practice of medicine in the U.S. is determined at the state level and defined by each state medical board, thus resulting in limitations in geographic and population scaling. Similarly, healthcare systems vary among countries. The rapid growth of technologyenabled healthcare will create increased pressure on traditional licensing bodies to reform laws and policies allowing some form of telehealth practice of medicine and other healthcare across state lines and borders within the EU.

\section{Cost-Benefit Analysis of New Legislative Proposals}

The U.S. Congressional Budget Office (CBO) produces independent formal cost projections for every bill approved by Congress, including telehealth-related legislation. Although aided by a panel of 22 advisors from a variety of healthcare fields, the CBO's process of formulating cost estimates excludes many potential effects of healthcare and telehealth policy. None of the 21 cost estimate reports on telehealth legislation issued by the $\mathrm{CBO}$ in the last decade included an in-depth analysis of cost savings, efficiency, or qualitative impacts. By focusing largely on the short-term financial costs of new legislation, the $\mathrm{CBO}$ did not consider potential cost savings, potential increases in the efficiency of healthcare resource use, or the value of quality improvements often 
1769. Dinesen. Personalized

https://doi.org/10.30953/tmt.v2.18

Page 9 of 38

associated with implementation of telehealth programs.

Lack of cost-benefit analysis stymied past efforts to improve telehealth policies at the federal level and hindered adoption and growth of telehealth programs across the nation. In contrast, European countries, such as the UK, Denmark, France, Germany, and Sweden, have long-standing Health Technology Assessment (HTA) organizations that advise government bodies on the costs and benefits of potential health technology treatments. HTA organizations estimate the value of better clinical outcomes using quality-adjusted life years (QALYs), healthy years equivalent (HYE), and disabilityadjusted life years (DALYs), among others, which weigh potential qualitative effects of healthcare treatments and technologies against potential financial costs.

\section{Telehealth Approaches for Cross-Sector Care Integration}

In the U.S. and the EU, hospitals and public healthcare systems tend to be fragmented between hospitals and municipally-based healthcare services. Among fragmented healthcare systems in the countries within the EU and in individual states in the U.S., the use of telehealth technologies can create jurisdictional conflicts, policy conflicts, and remain tangential to care practices rather than integrated into healthcare infrastructure.

Collectively, barriers to integration may slow development of a common vision for care, treatment, and rehabilitation of patients and minimize collaborative care among healthcare professionals across sectors. ${ }^{38}$

Healthcare organizations in the U.S., such as Kaiser Permanente or the Veterans Health Administration (VHA), have a single healthcare system: the hospital, district nursing, healthcare center, and primary care providers are integrated into a single organization. Such large systems also have a single, unified information technology system, an electronic health record (EHR) to coordinate and plan patients' care, tend to have a high degree of adoption of telehealth solutions for patients with chronic diseases, and utilize a more innovative approach to testing new models of care based on patients' preferences for using telehealth technologies within the healthcare system. 
1769. Dinesen. Personalized

https://doi.org/10.30953/tmt.v2.18

Page 10 of 38

In the U.S. and the EU, telehealth technologies are being tested in innovative ways to maximize emerging care models, including redesign of chronic disease management and the improvement of cross-sector care management. Examples of new models of care using telehealth technologies are home hospitalization of cardiac patients, ${ }^{30}$ preventive home monitoring of patients with COPD, ${ }^{40}$ and telerehabilitation of cardiac patients. ${ }^{41}$

Over the last decade in the EU, information technology solutions and telehealth technologies have been integrated between hospitals and municipalities and have reached a higher degree of data integration and sharing for the benefit of coordination and collaboration between healthcare professionals across sectors in patient care processes.

Examples of large EU telehealth projects with technologies involving both hospitals and municipalities are Renewing Health, ${ }^{42}$ United4Health, ${ }^{43}$ and MasterMind. ${ }^{44}$ In the Renewing Health project, eight countries participated (Denmark, Italy, Sweden, Norway, Spain, Finland, Greece, and Germany). They targeted patients with COPD, diabetes, and heart diseases; and a total of 7000 patients were enrolled in the study. Results showed that the cross-sector telehealth solution led to a shift of tasks between healthcare professionals across sectors and there was an improvement in communication between professions and between sectors. ${ }^{42}$ Healthcare professionals reported that patients took greater responsibility for their own health when able to see their data. When patients could not see their data, the healthcare professionals felt that the patients were less responsible for their healthcare and two-way communication was limited. ${ }^{42}$

\section{Emerging Issues That Influence Telehealth Delivery}

Providing high-quality, accessible, and cost-effective healthcare remotely for a socially, economically, and financially diverse population presents challenges, within or between countries. The most substantial challenge is providing care for patients with chronic 
1769. Dinesen. Personalized

https://doi.org/10.30953/tmt.v2.18

Page 11 of 38

diseases. Half of patients in the U.S. have one or more chronic disease(s), accounting for $75 \%$ of the financial burden to the healthcare system. ${ }^{45}$ In the EU, $70 \%$ to $80 \%$ of healthcare budgets are spent on chronic diseases. ${ }^{46}$ Establishing ways to lessen the burden and provide for these care needs requires systems that offer timely access to care, engage patients to participate, and prevent patients from inappropriate service utilization such as unnecessary emergency room visits. Telehealth is a viable alternative to standard face-to-face healthcare provider interactions.

A commitment to establishing large healthcare communication networks exists. As networks have grown, patient-provider communication and handheld devices have been incorporated into chronic disease management. Mobile phone apps and Web-based programs allow patients to manage their chronic diseases at home. It is estimated that 93 million people in the U.S. have access to mobile phones, a number likely to increase in the future. ${ }^{47}$

Emerging telehealth technologies are not only smaller and more efficient (eg, offering office-based desktop computer consultation with providers through patient-specific devices), but include education for patients and may offer suggestions for change in disease-specific treatment. Key issues driving the future of telehealth include (1) personalization of healthcare; (2) matching patients with appropriate technologies; (3) optimal use of healthcare data, including a secure interface between patient-generated data and the HER; (4) new education paradigms for patients and providers; (5) new communities of knowledge and practice; (6) new care and business models tailored to sustainability and scalability of telehealth initiatives; (7) transfer of scientific knowledge from research to practice; and (8) innovative research methodologies within telehealth. Each of these issues are discussed subsequently.

\section{Personalization of Healthcare}

There is no "one-size-fits-all" approach to managing patient care with telehealth because chronic diseases management is diverse. For new technologies to succeed, they must accommodate a spectrum of user needs. Technology must engage patients 
1769. Dinesen. Personalized

https://doi.org/10.30953/tmt.v2.18

Page 12 of 38

in their care and enhance collaboration with the healthcare system or they are destined to fail. Patients need skills and tools to proactively apply vital technology information. In addition, patients need their use of new technology to be personally meaningful (ie, in terms of relevant self-care) because these devices can serve as an intrusion into the patient's daily life and must serve to bring their health into focus at a personal level, not define them based on their disease state.

For example, patients with diabetes clearly do not use technology in a uniform manner. Patients with type 1 diabetes engage in accepting their disease and adapt to living with their disease by checking their blood glucose and monitoring what they eat. ${ }^{48,49}$ These patients (usually younger and more adept at using handheld devices, mobile phone apps, and Web-based programs) tend to be earlier adopters of new technologies that help them log their caloric intake, follow finger-stick blood glucose samples, and monitor daily exercise routines. The key to successful technology-based treatment is getting these patients to participate in using monitoring systems and finding a way to provide ongoing feedback that keeps patients engaged. Providers must offer encouragement and meaningful insight into data throughout their progress or their continued participation may decline.

Patients with type 2 diabetes, who may be older and less familiar with technology, will likely apply technology differently. Some have been dealing with their disease for many years, whereas others are confronted by a diabetes diagnosis only when in their fifties or sixties. Technology might not be as attractive to this group of patients compared to younger patients. Some patients with type 2 diabetes may have lost limbs, suffer from neuropathy, or have visual problems secondary to long-standing uncontrolled blood glucose. These populations may require a different device and approach to using technologies. Access, familiarity with technology, ease of use, and size of text fonts are important. A range of devices should be available to meet the diverse needs of this group.

Currently, telehealth systems store information from multiple sources: patient-collected 
1769. Dinesen. Personalized

https://doi.org/10.30953/tmt.v2.18

Page 13 of 38

physiological data, laboratory data, behavioral information, medication dosages, subjective symptoms of hypoglycemia, event data (e.g., emergency room visits), and images (e.g., retinal or wound photos). ${ }^{50}$ An all-encompassing approach might benefit patients who are extremely well organized and can handle large amounts of data, but some patients might be overwhelmed and not participate in telehealth.

Ultimately, there must be a match between technology, personalization, and the patients' needs and wishes. Providers must match the proper device and data management approach to the proper patient. Healthcare providers need to be aware that some patients use telehealth to contact with their providers and will also visit a nearby center for a face-to-face follow-up at the same time and for the same health issue.

\section{Matching Patients with Appropriate Technologies}

As telemedicine and telecommunication are lauded as possible solutions to the emerging shortage of healthcare providers, we must be cognizant that the use of technology in place of a face-to-face encounter will not be as easy for some patients.

The U.S. population is increasing and is estimated to grow by $20 \%$-to 363 million-by the year 2030. ${ }^{51}$ The population is aging as well and those aged 65 years and older (12.4\% of the population in 2000 ) will likely make up $19 \%$ of the U.S. population by 2030. Accompanying this aging population is an increase in chronic health conditions and expenditures associated with chronic disease management. Novel telehealth platforms require a match based on patient's age, education, interests, physical capabilities, familiarity, access to technology, and support to help with self-care and functional independence. Computer-based desktop apps with large screens and static interaction may be best suited for an aged population of patients with limited dexterity and visual limitations. For the elderly, the user interface often needs to be simple, easy to use, and provide meaningful interaction and feedback. Devices that allow patients to follow a script and alter care based on physiological information must be efficient and user-friendly. Perceptual, motor, and cognitive abilities should be considered when 
1769. Dinesen. Personalized

https://doi.org/10.30953/tmt.v2.18

Page 14 of 38

matching technology to patients.

A younger population exposed to such technological advances are more likely to use this type of monitoring device. The ability to follow one's progress, compete with other patients in attaining preset goals, and receive immediate feedback would seem attractive to this younger group. Beyond establishing patient-device symbiosis, researchers must weigh the intrusive nature of these devices and match patients who appreciate constant oversight with those who would prefer a more discrete means of monitoring.

There is a distinct dichotomy between those patients who greatly enjoy having a daily reminder to take their pills, exercise, and eat right versus those who appreciate some early instruction and then prefer to drop monitoring altogether. Establishing patient preference in that arena also takes time and effort, and the original protocol for the patient might need to be altered. Either way, we must strive to provide patients with devices that maximize success by applying their strengths and avoiding reliance on functional weaknesses.

Matching patients with a proper device and gathering large amounts of meaningful data will lead to improved insight into a person's disease state and better assessment of the success of care management strategies. For example, the VHA established the first large-scale use of telehealth in 1977. In 2013, more than 600,000 veterans accessed VHA healthcare using a telehealth program. Established in 2003, the VHA Care Coordination/Home Telehealth ( $\mathrm{CCHT}$ ) network provides routine noninstitutionalized care, and targets care management for patients with diabetes, chronic heart failure, hypertension, posttraumatic stress disorder, COPD, and depression. VHA Care Coordination/Home Telehealth uses remote monitoring devices placed in the veteran's home to communicate health status and transmit biometric data monitored remotely by care providers. ${ }^{44}$

More than 70,000 patients participate in this program, which is projected to reach more 
1769. Dinesen. Personalized

https://doi.org/10.30953/tmt.v2.18

Page 15 of 38

than 92,000 patients in the next few years. Analysis of ongoing data has allowed the VHA to change their approach and management strategies, and makes the home the preferred place of care whenever possible and appropriate. Through use of telehealth, the VHA telehealth program reduced admissions by $20 \%$ in $2010 .{ }^{52}$ Patients with diabetes had a $20 \%$ decrease in resource utilization, those with heart failure had a $30 \%$ reduction, and those with depression had a $56 \%$ reduction. ${ }^{9}$ Patient satisfaction remained above $86 \%$, and all but $10 \%$ were willing to participate in the program. Analysis of patients who utilized the program suggests that the quality of care and patient-specific outcomes have not been compromised by the CCHT model. As the VHA program continues to grow, it will be increasingly successful in gathering and analyzing telehealth data to better serve future patients with chronic diseases.

Optimal Use of Health Care Data and Secure Interface Between Patient-Generated Data and the Electronic Health Record

Large health systems have much to gain by providing increased communication and patient engagement through mobile devices and Web-based interfaces. Beyond chronic disease management, secure methods of data capture working directly with patients open major opportunities for wellness and health maintenance initiatives, as well as dynamic participation in research. ${ }^{53,54}$

Yet, there remain concerns regarding ownership and obligations inherent in communication of personal health data by health systems for data collected through patients' mobile devices. Health systems are exploring fundamental issues such as when ownership of patient-provided data begins and its scope. Given the need for thirdparty telecommunications carriers to support the connectivity of personal devices, and often independent developer apps to manage local capture of data, there remains a lack of clarity regarding the conditions under which personal data becomes protected data and the legal obligations this imposes on health policies such as the Health Insurance Portability and Accountability Act (HIPAA)..$^{53}$

Adding to this challenge are the many patients and health advocates who are frustrated 
1769. Dinesen. Personalized

https://doi.org/10.30953/tmt.v2.18

Page 16 of 38

by lack of accessibility to their own personal health information and associated overprotection of such information by privacy laws and paternalistic health institutions. This is a two-fold challenge: determining ownership and, ultimately, indemnity for data collected by and from patients, while also deciding on strategies for data that are further aggregated and integrated with different sources within clinical systems. This dual challenge has influenced the lack of broader dissemination to date. Healthcare systems are inherently risk-averse. They struggle to keep up with the broad opportunities offered by these emerging technologies.

Two routes for obtaining patient-contributed data predominate: active participation, in which patients fill out and upload their own health information or test results, and passive participation, in which patients provide data through monitoring devices or other mechanisms that have limited interaction other than aggregate viewing (e.g., personal fitness monitors). Both routes of collecting personal health data and the risk-averse policies of institutions are helping clarify principles of data management. Health providers are moving toward support of a full and auditable "chain of custody" or data provenance support for patient communications in anticipation that healthcare communication derived from data may be called into question. ${ }^{55}$ It should be noted that data provenance has a secondary benefit. It improves the ability to define and address measures of quality and communications.

At an organizational level, both means of collecting personal health data are altering the roles of institutional data handlers, such as hospitals, clinicians, and testing companies, and are leading to changes in determining ownership of health data. Among proponents of personal ownership of health data, the removal of intermediaries is a strength because it empowers individuals to control and deploy their information for chosen purposes. However, there remain concerns that personal ownership will negatively impact the quality of data and have a subsequent impact on data quality used for the practice of healthcare.

Increasingly, patients are tracking their health status and incorporating lifestyle 
1769. Dinesen. Personalized

https://doi.org/10.30953/tmt.v2.18

Page 17 of 38

information into their overall health management. For the most part, innovation is taking place in the social media and has not been integrated into clinical care. Likewise, community-level data inform and shape health trajectories and health policies and are not well integrated into clinical care. Achieving individual and community improvements in health depends on building capacity to integrate data across sources into actionable packages so that individuals can act to improve their own health and communities can plan and deploy resources and policies to address barriers and facilitators to health attainment.

The incorporation of technology into healthcare settings, such as adoption of EHRs, has grown in the past few years, with nearly $40 \%$ of all physicians adopting basic EHR capabilities. Original policies pertaining to EHR technology created incentives and penalties that put an overwhelming emphasis on provider-centric health information technology (HIT), with EHR systems built to give providers better access to information and improved methods of storing and sharing that information between providers. The focus was placed on provider adoption, with minimal incentive for patients to engage and use the system. Notably absent in the legislation and goals of federal HIT is the voice of the patient in creating HIT that meets the needs of patients and can lead to meaningful health outcomes. The lack of focus on patients has come to the attention of numerous groups, including the American Telemedicine Association and Healthcare Information and Management Systems Society, which have joined five industry groups in advocating the inclusion of standards that require EHR to incorporate patientgenerated data from remote monitoring devices.

Underlying this advocacy is the belief that the value of extending HIT requirements to include patient-generated data and data collected outside of traditional office visits will be realized through increased efficiency of delivery of healthcare services and systems that support timely exchange of data and information to improve health outcomes. Chronic disease registries and websites could accelerate progress in mobilizing appropriate evidence-based care in a timely fashion, promoting communication among the care team, and helping to design community or population-level interventions to 
1769. Dinesen. Personalized

https://doi.org/10.30953/tmt.v2.18

Page 18 of 38

improve health.

\section{Creating New Education Paradigms for Patients}

Mobile phone and other handheld applied telehealth-based instruments can be used as electronic (e)-learning tools for patient education, mobile clinical communication, and disease self-management education. When emerging telehealth tools and devices store a great amount of information, they can become the source tool for information sharing and education in examination rooms and at hospital bedsides, and electronically through e-transfer of information. Large wall- and desk-mounted screens are common in healthcare centers, and home televisions now have monitor functions. When telehealth tools are connected, the education experience may be enhanced.

Data from mobile phones and internal or external telehealth instruments can be linked to desk-based or free-standing kiosk education devices or centers that will be prevalent in ambulatory centers of the future, and may even be tied into self-service electronic systems used to check-in to appointments, request medication refills, and provide other healthcare purposes. Patients with in-dwelling or externally applied cardiac (or other) devices that store data or allow for transfer of data to an external storage system will be able to access a kiosk-like education system, retrieve or synchronize data, receive education about the meaning of data, and receive instructions about the plan of care based on e-data findings.

Plans for care, as part of the system, would have been previously vetted by healthcare professionals and be based on individualized algorithms to enhance safety and decrease the risk of harm. The innovative education roles of mobile phones and other technology continue to evolve with new software, hardware, innovative storage solutions, and patient confidentiality solutions.

There are many examples of e-learning tools in development and testing. In one report, ${ }^{48}$ researchers explored an application of Web 2.0 integrated with Internetprotocol television for personalized home-based health information in diabetes 
1769. Dinesen. Personalized

https://doi.org/10.30953/tmt.v2.18

Page 19 of 38

education among adults who were not strong computer and Internet users. This intervention provided diabetes educator-delivered, personalized health information directly to patients in their homes through an enhanced home television screen and remote control. The goal was to build health literacy and knowledge about diabetes management.

After testing the system, researchers concluded that the system had educational potential. ${ }^{56}$ In another study, parents of babies with infantile hemangiomas were trained to assess their children's skin abnormalities for early complications through an elearning module or by a dermatologist-delivered e-consultation. ${ }^{57}$ After e-learning, parents' judgments about diagnosis were in concordance with those of the dermatologist in $96 \%$ of the cases. Results indicate that correct diagnosis via e-learning can promote earlier recognition and treatment of infantile hemangioma risk factors and complications.

As new education paradigms emerge that use telehealth and other digital technology, it is important to recognize the digital divide among patients. Those patients especially at risk of negative health outcomes could benefit most from telehealth tools. A qualitative analysis to gain better insight on the digital divide of patients demonstrated that patients' gaps in knowledge of technology are greatest at three points: (1) in the clinical setting, when patients' preexisting personal barriers to care are exacerbated; (2) during screening; and (3) during physician-patient follow-up. ${ }^{58}$ Technology knowledge gaps can create confusion and fear, and patients may have low confidence in the quality of the content. Thus, when new education paradigms are created, overcoming the digital divide must be considered.

\section{Creating New Education Paradigms for Health Care Providers}

Mobile phones and other emerging handheld devices are powerful and useful professional education tools for healthcare providers. Professional literature and educational materials can serve as conduits for information that enhance the practice of evidence-based medicine, provide professional education, act as a mobile clinical 
1769. Dinesen. Personalized

https://doi.org/10.30953/tmt.v2.18

Page 20 of 38

communication aid (with other healthcare professionals or office and hospital colleagues), store disease self-management education materials, and allow remote (live or streamed) patient education.

Apps are becoming more sophisticated and include static or motion images, such as in ophthalmological examinations, ${ }^{59}$ trauma in rural settings. ${ }^{60}$ and mobile phone and other telehealth tools served for multiple emerging purposes, including healthcare provider education. Adoption of high technology medical communication-in addition to highperformance computers, fiber optic equipment, and high-resolution cameras-enables greater capacity for collaboration and learning between healthcare providers.

\section{Forming Communities of Knowledge and Practice}

Given the significant changes in telehealth and telehealth applications brought about by the rapid emergence of healthcare organizational change, new software apps, new devices, and new forms of data, it is important for providers to form communities of expertise in applying the most recent scientific advances.

App developers are rarely healthcare experts, and patients may forget the "buyer beware" motto associated with software purchase or free downloading. One case in point is that of apps for pain, $80 \%$ of which are available for iPhones. Researchers found 220 apps, $80 \%$ of which were built on the iOS platform and ranged in price from free/nominal cost (generally less than U.S. \$5) to as much as U.S. \$90. Unfortunately, in $65 \%$ of the apps identified, there was no evidence of healthcare provider involvement in development, even though the primary purposes of these apps were pain education (24.1\%), self-management of pain $(62.3 \%)$, or both $(13.6 \%){ }^{61}$

Further, not all telehealth systems successfully meet educational or behavioral outcomes. When telephone-based reminders and Web-based educational tools were used to improve medication adherence for acne treatment, only the Web-based educational tools had a positive effect. ${ }^{62}$ When home video telehealth and monthly telephone counseling, respectively, were used to maintain weight in African-American 
1769. Dinesen. Personalized

https://doi.org/10.30953/tmt.v2.18

Page 21 of 38

women, there were no differences in outcomes for the two methods; however, valid digital video recorder use during the intervention period was reported as low, ranging from zero to $42 \%$ use per participant. ${ }^{63}$

In an 18-month longitudinal study of telehealth for diabetes management, patients using telehealth required less support in physical activity, healthy eating, and problem-solving behaviors than control participants, but more support in medication adherence and healthy coping. ${ }^{64}$ It might be that telehealth users became dependent on telehealth to promote medication adherence and provide coping advice.

Although medication reminders and coping advice are beneficial, patients should become more independent in self-care over time and be able to overcome routine problems that come with managing diabetes. It will be important to conduct research on a range of telehealth education paradigms and tools to identify attributes of successful training paradigms and ensure that there are no issues related to the digital divide.

As telehealth becomes more prevalent, it will be important to ensure that communities of experts with knowledge of and experience with specific patient populations can develop systems and processes that ensure excellence in educational message content and can match the proper telehealth system with the intended education and clinical outcomes. It is important to use communities of experts to reassess the effectiveness of education content at frequent, regular intervals to ensure that best practice and evidence-based information are used, further ensuring that education (and selfmanagement based on education) will promote optimal clinical and behavioral outcomes.

In addition, as e-learning tools become more prevalent in private homes, there will be a greater need for communities of knowledge and practice related to privacy and information security. In a study of home rehabilitation programs for chronic pulmonary disease and diabetes, an assessment was made of e-diaries used to communicate with healthcare professionals, focusing on privacy, security, and risks to information security. 
1769. Dinesen. Personalized

https://doi.org/10.30953/tmt.v2.18

Page 22 of 38

Threats identified regarding data included those related to confidentiality, integrity, availability, and quality. From the perspective of a technical platform, the issue of confidentiality was identified as the most serious, in one case reaching an unacceptable "high-risk" level. Telehealth in the home offers additional threats to privacy and confidentiality compared to hospitals and healthcare centers that have controlled environments. Consequently, telehealth will require commensurate levels of information security to support the rapid adoption of emerging telehealth tools.

New Care and Business Models Tailored to Sustainability and Scalability of Telehealth Initiatives

To reduce risks and costs when starting a new telehealth service, it is useful to develop new care and business models to increase the probability of success.

To understand the dynamic and workflow of telehealth among healthcare professionals and within healthcare systems, a new theoretical framework for understanding crosssector care integration must be developed. One way to develop a framework is to employ an interorganizational approach, such as that used in the eHealth-enhanced Chronic Care Model. ${ }^{65} \mathrm{~A}$ new framework should address specific approaches for crosssector care integration, redesign of chronic disease care management, and redesign of multiple care practices through telehealth.

Most of today's telehealth solutions are designed to provide monitoring functionality for a single chronic disease, even though most elderly adults have multiple chronic medical conditions. In the future, chronic disease management through telehealth technologies must be versatile in functionality and support patients with multiple diseases. Systems must provide more options or become more patient-specific and personalized. Stratification tools are needed for matching patient preferences and healthcare providers' recommendations to specific technology. Guidelines that assist patients in understanding how to use the technology, how data are analyzed, and how to selfmonitor must be developed to help patients obtain a higher degree of self-management. 
1769. Dinesen. Personalized

https://doi.org/10.30953/tmt.v2.18

Page 23 of 38

There exists no common conceptualization of business models and cases for telehealth in the literature. ${ }^{66}$ However, it is important to break down the business model and business cases into components to understand and then construct sustainable and scalable telehealth initiatives. Sustainable business models must be developed to meet the demands of the many stakeholders in telehealth programs and create value for a company as well as the healthcare sector and patient.

There is limited research on the use of business models and cases in telehealth. However, identification of innovative telehealth business models is of interest globally. The question is whether it is possible to develop a general model that can be used across countries and still be sensitive to different legal and operational structures of reimbursement and varied socioeconomic contexts between developed and developing countries. For example, the lack of transportation in developing countries will place a higher emphasis on critical access to basic healthcare, whereas the value proposition in a developed country would more likely emphasize convenience of location. ${ }^{64}$

Self-tracking technologies are expected to change the role of the consumer because the consumer will deal directly with the companies selling medical devices or devices for tracking pulse, sleep, etc.

Innovative Research Methodologies Within Telehealth

Evaluation of the efficacy of telehealth has been carried out within the traditional research paradigm using randomized controlled trials (RCTs). RCTs are considered the highest level of evidence because of their high level of internal validity, but they are both expensive and time-consuming. With technologies being developed, the RCT evaluation paradigm may become too cumbersome and time-consuming for stakeholders and managers within the healthcare system, and policy makers often do not have time to await a scientific assessment of a given technology before they have to decide on budgets for the coming financial year. Alternatively, managers prefer evidence-based decision making and may request information about clinical impact, cost-effectiveness, 
1769. Dinesen. Personalized

https://doi.org/10.30953/tmt.v2.18

Page 24 of 38

patient perception, and organizational aspects of telehealth. This was demonstrated by Kidholm et al. ${ }^{67}$ in a study of European healthcare managers.

Globally, there is discussion about developing a new framework for assessing telehealth technologies at different levels of development. Within the EU, a new multimodal telehealth assessment tool called the Model for Assessment of Telemedicine Applications (MAST) provides a multidisciplinary assessment of telehealth technologies. ${ }^{68}$ The assessment process has three steps. First, preliminary assessment where the maturity of the technology and the organization using it is assessed (eg, in the form of a feasibility study). Second, a multidisciplinary assessment of outcomes of the telehealth application within seven domains: (1) health problem and characteristics of the application, (2) safety, (3) clinical effectiveness, (4) patient perspectives, (5) economic aspects, (6) organizational aspects, and (7) sociocultural, ethical, and legal aspects. The third assessment where a transferability assessment of evidence to the local setting is considered.

The MAST model is the most widely used framework for evaluating telemedicine in the EU and is used in a number of EU projects. Examples of MAST are available in studies by Minet et al. ${ }^{69}$ and Rasmussen et al. ${ }^{70}$

Transfer of Scientific Knowledge: From Research to Implementation and Practice Telehealth offers the opportunity to deliver care that is accessible, convenient, and patient-centered, overcoming many of the barriers inherent in traditional healthcare delivery systems. ${ }^{71}$ However, widespread implementation requires attention to systems engineering approaches to healthcare design so it can address incentives, technical and human requirements, work processes, and payment issues. ${ }^{72}$

To demonstrate and realize added value to health outcomes, telehealth implementation is not simply a feature to be added to existing healthcare delivery. It must be integrated at the system level. Integration involves examining the current flow of care for targeted subpopulations and revising the overall approach to care, integrating telehealth, and 
1769. Dinesen. Personalized

https://doi.org/10.30953/tmt.v2.18

Page 25 of 38

changing traditional elements. For example, using telehealth to manage chronic disease might incorporate interprofessional involvement, with nurses, pharmacists, or dietitians coaching patients through telehealth between visits for primary care. Integration may require challenging adjustments in the current delivery of care. For example, the number of planned primary care visits may be reduced as telehealth is used to augment care.

For telehealth to fully integrate into global health systems, a number of items that support system transformation is needed. Given that telehealth often includes patientgenerated data, significant changes will be needed to ensure accurate, efficient, and timely monitoring of health parameters that are useful for guiding clinical decision making. Integration and interpretation of these data are essential to optimizing telehealth, yet many EHR systems lack the capacity to incorporate patient-generated data or are unable to make it available in a time-sensitive fashion.

Similarly, new competencies will be required for healthcare professionals in telehealth and systems engineering to improve health. ${ }^{72}$ Finally, telehealth research must promote approaches to care that are amenable for adoption in practice. The age-old challenge is to translate research findings into practice to facilitate adoption of new knowledge to telehealth. The challenges are to reinforce the urgency with which evidence is needed to drive policy and provide greater incentive for researchers and practitioners to collaborate.

\section{American and European Visions for Personalized Telehealth}

In the U.S., the Health Resources and Services Administration works to increase and improve the use of telehealth to meet the needs of underserved people, including those living in rural and remote areas, with low income, uninsured, or those enrolled in Medicaid. The Affordable Care Act was intended to drive changes in healthcare delivery that bring greater value and access, particularly to populations who require complex care. 
1769. Dinesen. Personalized

https://doi.org/10.30953/tmt.v2.18

Page 26 of 38

As reimbursement moves from fee-for-service to value-based and outcome-driven payment, incentives for providing telehealth should improve. Through the Federal Office of Rural Health Policy and the Office for the Advancement of Telehealth (OAT), resources are provided in the U.S. to support regional telehealth technical assistance centers, a national telehealth policy center, and a national telehealth technology assistance center. In addition, OAT provides grants for creation of evidence-based teleemergency networks and demonstration projects to test telehealth networks in improving healthcare services for medically underserved populations in urban, rural, and frontier areas of the country.

The World Health Organization (WHO) has developed a European policy framework and strategy for the 21st century called "Health 2020." The vision is to achieve the highest level of health among European countries and improve health for all citizens, and reduce health inequalities, empower citizens to take care of their own health, and strengthen people-centered health system and public health capacity. ${ }^{73}$ In 2011 , WHO launched a policy on health technology assessment of medical devices with a focus on this area because new technologies are evolving rapidly. ${ }^{74}$

Similarly, the EU Commission launched an eHealth Action Plan for 2012-2020 entitled "Innovative Healthcare for the 21st Century in the EU."75 This plan seeks to improve chronic conditions, multiple morbidity management, and strengthen prevention; increase patient/citizen-centric care via citizen empowerment and organizational sustainability; stimulate cross-border healthcare, security, and equity; and improve legal and market conditions for developing eHealth products and services. ${ }^{75}$

Finally, Denmark has a national strategy to digitalize the Danish public sector by $2020 .^{76}$ Focus is on implementing telehealth at scale, improving personalized telehealth, quality of life for patients and citizens within the healthcare and social sectors, and to increase the efficiency and effectiveness of workflows within the public sector.

Within the EU, the "Horizon 2020" research program offers funding possibilities to 
1769. Dinesen. Personalized

https://doi.org/10.30953/tmt.v2.18

Page 27 of 38

facilitate more telehealth projects at scale, with an implementation focus, and for international (U.S. and EU) partners. The TTRN advocates more transatlantic telehealth studies to develop synergy in research and gain generalizable results at a more rapid pace.

\section{Personalized Telehealth in the Future: A Global Research Agenda}

As telehealth plays a greater role in global healthcare delivery, it is important to develop a strong evidence base of successful, innovative telehealth solutions that lead to scalable and sustainable telehealth programs. A broad, multinational research agenda can provide a uniform framework for identifying and rapidly replicating best practices, while concurrently fostering global collaboration in the development and rigorous testing of new and emerging telehealth technologies.

As an initial effort toward a global research agenda, the members of the TTRN offer a 12-point research agenda that incorporates healthcare parameters across mediated and traditional modes of care for the benefit of providers, companies, policy makers, and the international research community (Table 1).

Table 1. Areas for personalized telehealth research. 
1769. Dinesen. Personalized https://doi.org/10.30953/tmt.v2.18 Page 28 of 38

\begin{tabular}{|c|c|}
\hline Focus & Research Agenda \\
\hline Patient & $\begin{array}{l}\square \text { list-behavior=unordered prefix-word= mark-type=disc } \\
\square \text { Assessment of personal engagement in own health through the use of telehealth } \\
\text { technologies (quantified self) } \\
\square \text { Self-determination and motivation regarding use of new telehealth technologies } \\
\square \text { Health literacy, eHealth literacy, technology literacy, contributions to design } \\
\text { features of technology, and interaction with telehealth technologies } \\
\square \text { Patient-to-patient interventions }\end{array}$ \\
\hline Home & $\begin{array}{l}\square \text { list-behavior=unordered prefix-word= mark-type=disc } \\
\square \text { Integration of smart home telehealth technologies (wellness and health devices } \\
\text { and software, Internet of Things) }\end{array}$ \\
\hline $\begin{array}{l}\text { Healthcare } \\
\text { professionals }\end{array}$ & $\begin{array}{l}\square \text { list-behavior=unordered prefix-word= mark-type=disc } \\
\text { Communication for and between providers and patients (telehealth through } \\
\text { mobile, wearable, and remote monitoring) } \\
\square \text { Telehealth training and education, including designing communities of knowledge } \\
\text { and practice }\end{array}$ \\
\hline $\begin{array}{l}\text { Health system } \\
\text { design, } \\
\text { organization, } \\
\text { and practice }\end{array}$ & $\begin{array}{l}\square \text { list-behavior=unordered prefix-word= mark-type=disc } \\
\square \text { Cross-sector integration using telehealth technologies (Accountable Care } \\
\text { Organizations, bundled care, medical homes) } \\
\square \text { Telehealth in redesign of chronic disease management } \\
\square \text { Adoption of telehealth programs in clinical practice }\end{array}$ \\
\hline Technologies & $\begin{array}{l}\square \text { list-behavior=unordered prefix-word= mark-type=disc } \\
\square \text { Use of self-tracking technologies } \\
\square \text { Design of user-friendly technologies } \\
\square \text { Develop sensor technologies to detect fluid in the body, sleep patterns, etc }\end{array}$ \\
\hline $\begin{array}{l}\text { Data systems } \\
\text { and } \\
\text { infrastructure }\end{array}$ & $\begin{array}{l}\square \text { list-behavior=unordered prefix-word= mark-type=disc } \\
\square \text { Integrate telehealth devices with electronic health records and cloud databases } \\
\square \text { Integration of personal health records data and telehealth devices and systems }\end{array}$ \\
\hline Data analytics & $\begin{array}{l}\square \text { list-behavior=unordered prefix-word=mark-type=disc } \\
\square \text { Algorithms for multi-model data platforms, devices, and sources } \\
\square \text { Innovative data analytic approaches for integrating data for precision medicine, } \\
\text { including predictive, personalized, and customized analytics }\end{array}$ \\
\hline $\begin{array}{l}\text { Development } \\
\text { of new } \\
\text { telehealth } \\
\text { technologies }\end{array}$ & $\begin{array}{l}\square \text { list-behavior=unordered prefix-word=mark-type=disc } \\
\square \text { Assessing mobile, intelligent, and individualized telehealth technologies } \\
\square \text { Enhancing the matching of patient preferences and telehealth use } \\
\square \text { Anticipation of telehealth innovations still to be invented } \\
\square \text { International telehealth technology standards }\end{array}$ \\
\hline $\begin{array}{l}\text { Research } \\
\text { methods }\end{array}$ & $\begin{array}{l}\square \text { list-behavior=unordered prefix-word= mark-type=disc } \\
\square \text { Multidisciplinary assessment of the effectiveness of new telehealth services } \\
\square \text { Advances in tracking, data transmission, and storage of telehealth data (real-time } \\
\text { analytics vs store-and-forward) } \\
\square \text { Rapid cycle design evaluation vs traditional randomized controlled trials }\end{array}$ \\
\hline Financing & $\begin{array}{l}\square \text { list-behavior=unordered prefix-word= mark-type=disc } \\
\square \text { Assessing innovative payment and reimbursement systems, especially in the } \\
\text { emerging value-based health care environment } \\
\square \text { Global variations in financing and paying for telehealth }\end{array}$ \\
\hline $\begin{array}{l}\text { Privacy and } \\
\text { security } \\
\text { policy }\end{array}$ & $\begin{array}{l}\square \text { list-behavior=unordered prefix-word= mark-type=disc } \\
\square \text { Addressing different cultures of privacy (ethical issues) for patients } \\
\square \text { Enhancing telehealth data security (given advances in mobile, wearable, and } \\
\text { cloud-based system configurations) } \\
\square \text { Local, regional, international regulatory requirements (licensing, guidelines, } \\
\text { standards) }\end{array}$ \\
\hline Public policy & $\begin{array}{l}\square \text { list-behavior=unordered prefix-word= mark-type=disc } \\
\square \text { Telehealth across state and international borders } \\
\square \text { Professional licensing and standards } \\
\square \text { Variation in interqovernmental and international telehealth policies and financi }\end{array}$ \\
\hline
\end{tabular}


1769. Dinesen. Personalized

https://doi.org/10.30953/tmt.v2.18

Page 29 of 38

The research goals are designed to facilitate comparative evaluations of telehealth solutions at multiple levels, from individual to system level, using a variety of devices and technologies, and in multiple settings and contexts. Although this research agenda requires specific refinements to address country and health system variations, it can provide a comprehensive orientation for pursuing global research in personalized telehealth.

\section{Affiliations}

Birthe Dinesen, Laboratory of Assistive Technologies - Telehealth \& Telerehabilitation, SMI, Department of Health Science and Technology, Aalborg University, Fredrik Bajers vej 7, Aalborg, 9220, Denmark, Phone: 45 20515944, Fax: 45981540 08, Email: kd.uaa.tsh@dib.

Copyright $^{\odot}$ Birthe Dinesen, Brandie Nonnecke, David Lindeman, Egon Toft, Kristian Kidholm, Kamal Jethwani, Heather M Young, Helle Spindler, Claus Ugilt Oestergaard, Jeffrey A Southard, Mario Gutierrez, Nick Anderson, Nancy M Albert, Jay J Han, Thomas Nesbitt. Originally published in the Journal of Medical Internet Research (http://www.jmir.org), 01.03.2016.

This is an open-access article distributed under the terms of the Creative Commons Attribution License (http://creativecommons.org/licenses/by/2.0/), which permits unrestricted use, distribution, and reproduction in any medium, provided the original work, first published in the Journal of Medical Internet Research, is properly cited. The complete bibliographic information, a link to the original publication on http://www.jmir.org/, as well as this copyright and license information must be included.

\section{Acknowledgments}

For their support of the Transatlantic Telehealth Research Network (TTRN), we wish to 
1769. Dinesen. Personalized

https://doi.org/10.30953/tmt.v2.18

Page 30 of 38

thank Mikkel Skovborg, Research Attache of the Danish Agency for Science,

Technology and Innovation, Palo Alto, CA; Theresa Hoegenhaugh, Regional Project Manager, Invest in Denmark; Eir Research \& Business Park, The European Regional Development Fund and participating universities and hospitals in Denmark and the U.S.

\section{References}

1. Bashshur RL, Shannon GW, Krupinski EA, et al. National telemedicine initiatives: essential to healthcare reform. Telemed J E Health. 2009;15(6):600-610.

2. Freiburger G, Holcomb M, Piper D. The STARPAHC collection: part of an archive of the history of telemedicine. J Telemed Telecare. 2007;13(5):221-223.

3. Bartolini E, McNeill N. The Network for Excellence in Health Innovation. 2012. Jun 13, [2015-12-26]. Getting to value: eleven chronic disease technologies to watch http://www.nehi.net/publications/30-getting-to-value-eleven-chronic-diseasetechnologies-to-watch/view

4. Dang S, Remon N, Harris J, et al. Care coordination assisted by technology for multiethnic caregivers of persons with dementia: a pilot clinical demonstration project on caregiver burden and depression. J Telemed Telecare. 2008;14(8):443-447.

5 . Wootton R. Twenty years of telemedicine in chronic disease management--an evidence synthesis. J Telemed Telecare. 2012 Jun;18(4):211-220.

6. Benjamin RM. Multiple chronic conditions: a public health challenge. Public Health Rep. 2010;125(5):626-627. http://europepmc.org/abstract/MED/20873276.

7. Anderson N, Edwards K. Building a chain of trust: using policy and practice to enhance trustworthy clinical data discovery and sharing. Proceedings of the 2010 Workshop on Governance of Technology, Information and Policies; GTIP '10 Workshop on Governance of Technology, Information and Policies; Dec 7, 2010; Austin, TX. 2010. pp. 15-20.

8. Busse R, Blümel M, Scheller-Kreinsen D, Zentner A, The European Observatory on Health Systems and Policies. Tackling Chronic Disease in Europe: Strategies, Interventions and Challenges. Copenhagen: World Health Organization; 2010.

9. Darkins A, Ryan P, Kobb R, Foster L, Edmonson E, Wakefield B, Lancaster AE. Care coordination/home telehealth: the systematic implementation of health informatics, 
1769. Dinesen. Personalized

https://doi.org/10.30953/tmt.v2.18

Page 31 of 38

home telehealth, and disease management to support the care of veteran patients with chronic conditions. Telemed J E Health. 2008 Dec;14(10):1118-1126.

10. Sorknaes AD, Bech $M$, Madsen $\mathrm{H}$, et al. The effect of real-time teleconsultations between hospital-based nurses and patients with severe COPD discharged after an exacerbation. J Telemed Telecare. 2013 Dec;19(8):466-474.

11. Polisena J, Tran K, Cimon K, et al Home telehealth for chronic obstructive pulmonary disease: a systematic review and meta-analysis. J Telemed Telecare. 2010;16(3):120-127.

12. Boutwell A, Hwu S. Effective Interventions to Reduce Rehospitalizations: A Survey of the Published Evidence. Cambridge, MA: Institute for Healthcare Improvement; 2009. [2016-01-25]. http://www.academyhealth.org/files/SQII/STAARSurvey.pdf .

13. Zanaboni P, Wootton R. Adoption of telemedicine: from pilot stage to routine delivery. BMC Med Inform Decis Mak. 2012;12(1):1-9.

14. Lindeman D. Interview: lessons from a leader in telehealth diffusion: a conversation with Adam Darkins of the Veterans Health Administration. Ageing Int. 2010 Oct 2;36(1):146-154.

15. Rojas SV, Gagnon M. A systematic review of the key indicators for assessing telehomecare cost-effectiveness. Telemed J E Health. 2008 Nov;14(9):896-904.

16. Bondmass M, Bolger N, Castro G, Avitall B. The effect of physiologic home monitoring and telemanagement on chronic heart failure outcomes. J Adv Nurs. 1998;3(2):1-10. http://ispub.com/lJANP/3/2/6119.

17. Vaccaro J, Cherry J, Harper A, O'Connell M. Utilization reduction, cost savings, and return on investment for the PacifiCare chronic heart failure program, Taking Charge of Your Heart Health. Dis Manage. 2001 Sep;4(3):131-142.

18. Maiolo C, Mohamed El, Fiorani CM, De Lorenzo A. Home telemonitoring for patients with severe respiratory illness: the Italian experience. J Telemed Telecare. 2003;9(2):67-71.

19. Scalvini S, Capomolla S, Zanelli E, et al. Effect of home-based telecardiology on chronic heart failure: costs and outcomes. J Telemed Telecare. 2005;11 Suppl 1:1618.

20. Benatar D, Bondmass M, Ghitelman J, Avitall B. Outcomes of chronic heart failure. 
1769. Dinesen. Personalized

https://doi.org/10.30953/tmt.v2.18

Page 32 of 38

Arch Intern Med. 2003 Feb 10;163(3):347-352.

21. Southard BH, Southard DR, Nuckolls J. Clinical trial of an Internet-based case management system for secondary prevention of heart disease. $J$ Cardiopulm Rehabil. 2003;23(5):341-348.

22. Giordano A, Scalvini S, Zanelli E, et al. Multicenter randomised trial on home-based telemanagement to prevent hospital readmission of patients with chronic heart failure. Int J Cardiol. 2009 Jan 9;131(2):192-199.

23. Bashshur RL, Shannon GW, Smith BR, et al. The empirical foundations of telemedicine interventions for chronic disease management. Telemed J E Health. 2014 Sep;20(9):769-800.

24. Mistry H. Systematic review of studies of the cost-effectiveness of telemedicine and telecare. Changes in the economic evidence over twenty years. J Telemed Telecare. 2012 Jan;18(1):1-6.

25. Steventon A, Bardsley M, Billings J, et al. Whole System Demonstrator Evaluation Team Effect of telehealth on use of secondary care and mortality: findings from the Whole System Demonstrator cluster randomised trial. BMJ. 2012;344:e3874. http://www.bmi.com/cgi/pmidlookup?view=long\&pmid=22723612.

26. Cartwright M, Hirani SP, Rixon L, et al. Whole Systems Demonstrator Evaluation Team Effect of telehealth on quality of life and psychological outcomes over 12 months (Whole Systems Demonstrator telehealth questionnaire study): nested study of patient reported outcomes in a pragmatic, cluster randomised controlled trial. BMJ. 2013;346:f653. http://www.bmj.com/cgi/pmidlookup?view=long\&pmid=23444424.i

27. Henderson C, Knapp M, Fernández J, et al. Whole System Demonstrator evaluation team Cost effectiveness of telehealth for patients with long term conditions (Whole Systems Demonstrator telehealth questionnaire study): nested economic evaluation in a pragmatic, cluster randomised controlled trial. BMJ. 2013;346:f1035.

28. Hendy J, Chrysanthaki T, Barlow J, et al. An organisational analysis of the implementation of telecare and telehealth: the whole systems demonstrator. BMC Health Serv Res. 2012;12:403.

29. Sanders C, Rogers A, Bowen R, et al. Exploring barriers to participation and 
1769. Dinesen. Personalized

https://doi.org/10.30953/tmt.v2.18

Page 33 of 38

adoption of telehealth and telecare within the Whole System Demonstrator trial: a qualitative study. BMC Health Serv Res. 2012;12:220.

30. Or CK, Karsh B. A systematic review of patient acceptance of consumer health information technology. J Am Med Inform Assoc. 2009 Aug;16(4):550-560.

31. Berwick DM, Nolan TW, Whittington J. The triple aim: care, health, and cost. Health Aff (Millwood) 2008;27(3):759-769.

http://content.healthaffairs.org/cgi/pmidlookup?view=long\&pmid=18474969.

32. U.S. Department of Health and Human Services National Quality Strategy. 2011. Mar, [2015-12-26]. 2011 Report to Congress: national strategy for quality improvement in healthcare http://www.ahrq.gov/workingforquality/nqs/nqs2011annlrpt.htm

33. Center for Connected Health Policy State Telehealth Laws and Reimbursement Policies: A Comprehensive Scan of the 50 States and District of Columbia. 2015. Feb, [2016-01-25].

http://cchpca.org/sites/default/files/resources/State\%20Laws\%20and\%20Reimburse ment\%20Policies\%20Report\%20Feb\%20\%202015.pdf

34. Currie WL, Seddon JJ. A cross-national analysis of eHealth in the EU: Some policy and research directions. Inform Manage. 2014 Sep;51(6):783-797.

35. Doarn CR, Pruitt S, Jacobs J, et al. Federal efforts to define and advance telehealth-a work in progress. Telemed J E Health. 2014 May;20(5):409-418.

36. Moen A, HackI WO, Hofdijk J, et al. eHealth in Europe: status and challenges. Eur J Biomed Inform. 2012;8(1):2-7. http://www.ejbi.org/img/ejbi/2012/1/Moen en.pdf.

37. Kvedar J, Coye MJ, Everett W. Connected health: a review of technologies and strategies to improve patient care with telemedicine and telehealth. Health Aff (Millwood) 2014 Feb;33(2):194-199.

38. Dinesen B, Gustafsson J, Nøhr C, et al. Telehomecare technology across sectors: claims of jurisdiction and emerging controversies. Int J Integr Care. 2007;7:e43. http://europepmc.org/abstract/MED/18043726.

39. Dinesen B, Toft E. Telehomecare challenge collaboration among healthcare professionals. Wireless Pers Commun. 2009 Jul 7;51(4):711-724.

40. Dinesen B, Seeman J, Gustafsson J. Development of a program for tele- 
1769. Dinesen. Personalized

https://doi.org/10.30953/tmt.v2.18

Page 34 of 38

rehabilitation of COPD patients across sectors: co-innovation in a network. Int $J$ Integr Care. 2011 Jan;11:e012. http://europepmc.org/abstract/MED/21637709.

41. Dinesen B, Spindler H. Individualized telerehabilitation for heart patients across municipalities, hospitals and medical disciplines: preliminary findings from the Teledialog project. Int J Integr Care. 2014;14(8):10-11.

42. Kidholm K, Stafylas P, Kotzeva A, et al. Renewing Health: Final Report-Public version 1. 2014. Jun, [2016-01-25].

http://www.renewinghealth.eu/documents/28946/555381f3-9686-4955-854776b58be34a04.

43. United4Health. [2015-12-26]. http://united4health.eu/ .

44. MasterMind. [2015-12-26]. http://mastermind-project.eu/ .

45. Schaffer J. For The Record. 2012. Jul 30, [2016-01-25]. Emerging technologies for chronic disease care http://www.fortherecordmag.com/archives/073012p10.shtml .

46. European Commission The 2014 EU Summit on Chronic Diseases, Brussels, 3 and 4 April 2014: Conference Conclusions. 2014. [2016-01-25].

http://ec.europa.eu/health/major chronic diseases/docs/ev 20140403 mi en.pdf .

47. eMarketer. [2015-12-26]. http://www.emarketer.com/ .

48. Levin K, Madsen J, Petersen I, Wanscher C, Hangaard J. Telemedicine diabetes consultations are cost-effective, and effects on essential diabetes treatment parameters are similar to conventional treatment: 7-year results from the Svendborg Telemedicine Diabetes Project. J Diabetes Sci Technol. 2013 May;7(3):587-595. http://europepmc.org/abstract/MED/23759390.

49. Skrøvseth SO, Årsand E, Godtliebsen F, Joakimsen RM. Data-driven personalized feedback to patients with type 1 diabetes: a randomized trial. Diabetes Technol Ther. 2015 Jul;17(7):482-489.

50. Klonoff DC. Using telemedicine to improve outcomes in diabetes--an emerging technology. J Diabetes Sci Technol. 2009 Jul;3(4):624-628. http://europepmc.org/abstract/MED/20144303.

51. NTT Data NTT Data White Paper: Trends in Telehealth. 2014. [2016-01-25]. http://americas.nttdata.com/Industries/Industries/Healthcare/ /media/Documents/Wh ite-Papers/Trends-in-Telehealth-White-Paper.pdf . 
1769. Dinesen. Personalized

https://doi.org/10.30953/tmt.v2.18

Page 35 of 38

52. Broderick A. Case Studies in Telehealth Adoption. New York: The Commonwealth Fund; 2013. Jan, [2016-01-25]. The Veterans Health Administration: taking home telehealth services to scale nationally

http://www.commonwealthfund.org/ /media/Files/Publications/Case\%20Study/2013/ Jan/1657 Broderick telehealth adoption VHA case study.pdf.

53. Anderson N, Bragg C, Hartzler A, Edwards K. Participant-centric initiatives: tools to facilitate engagement in research. Appl Trans/ Genom. 2012 Dec 1;1:25-29.

54. Kaye J, Curren L, Anderson N, et al. From patients to partners: participant-centric initiatives in biomedical research. Nat Rev Genet. 2012 May;13(5):371-376.

55. Anderson G. Robert Wood Johnson Foundation. 2010. Chronic care: making the case for ongoing care http://www.rwjf.org/en/library/research/2010/01/chroniccare.html.

56. Greenwood DA, Young HM, Quinn CC. Telehealth remote monitoring systematic review: structured self-monitoring of blood glucose and impact on A1C. J Diabetes Sci Technol. 2014 Feb 21;8(2):378-389.

57. de Graaf M, Knol MJ, Totté JE, et al. E-learning enables parents to assess an infantile hemangioma. J Am Acad Dermatol. 2014 May;70(5):893-898.

58. George S, Moran E, Fish A, Ogunyemi L. Understanding the digital divide in the clinical setting: the technology knowledge gap experienced by U.S. safety net patients during teleretinal screening. Stud Health Technol Inform. 2013;192:946.

59. Zvornicanin E, Zvornicanin J, Hadziefendic B. The use of smart phones in ophthalmology. Acta Inform Med. 2014 Jun;22(3):206-209.

60. Zangbar B, Pandit V, Rhee P, et al. Smartphone surgery: how technology can transform practice. Telemed J E Health. 2014 Jun;20(6):590-592.

61. Wallace LS, Dhingra LK. A systematic review of smartphone applications for chronic pain available for download in the U.S. J Opioid Manag. 2014 Feb;10(1):63-68.

62. Park C, Kim G, Patel I, Chang J, Tan X. Improving adherence to acne treatment: the emerging role of application software. Clin Cosmet Investig Dermatol. 2014;7:65-72.

63. Gerber BS, Schiffer L, Brown AA, et al. Video telehealth for weight maintenance of African-American women. J Telemed Telecare. 2013 Jul;19(5):266-272.

64. Chen L, Chuang L, Chang C, et al. Evaluating self-management behaviors of 
1769. Dinesen. Personalized

https://doi.org/10.30953/tmt.v2.18

Page 36 of 38

diabetic patients in a telehealthcare program: longitudinal study over 18 months. $J$ Med Internet Res. 2013;15(12):e266.

65. Gee PM, Greenwood DA, Paterniti DA, Ward D, Miller LM. The eHealth Enhanced Chronic Care Model: a theory derivation approach. J Med Internet Res. 2015;17(4):e86.

66. Chen S, Cheng A, Mehta K. A review of telemedicine business models. Telemed J E Health. 2013 Apr;19(4):287-297.

67. Kidholm K, Ølholm AM, Birk-Olsen M, Cicchetti A, Fure B, Halmesmäki E, Kahveci R, Kiivet R, Wasserfallen J, Wild C, Sampietro-Colom L. Hospital managers' need for information in decision-making - An interview study in nine European countries. Health Policy. 2015 Aug 24;119(11):1424-1432.

68. Kidholm K, Ekeland AG, Jensen LK, et al. A model for assessment of telemedicine applications: mast. Int J Technol Assess Health Care. 2012 Jan;28(1):44-51.

69. Rosenbek ML, Hansen LW, Pedersen CD, et al. Early telemedicine training and counselling after hospitalization in patients with severe chronic obstructive pulmonary disease: a feasibility study. BMC Med Inform Decis Mak. 2015;15:3.

70. Rasmussen BS, Froekjaer J, Bjerregaard MR, et al. A randomized controlled trial comparing telemedical and standard outpatient monitoring of diabetic foot ulcers. Diabetes Care. 2015 Sep;38(9):1723-1729.

71. Lustig TA. The Role of Telehealth in an Evolving Health Care Environment: Workshop Summary (2012) Washington, DC: The National Academies Press; 2012.

72. President's Council of Advisors on Science and Technology Better Health Care and Lower Costs: Accelerating Improvement through Systems Engineering. 2014. May, [2015-10-15].

https://www.whitehouse.gov/sites/default/files/microsites/ostp/systems engineering and healthcare.pdf .

73. World Health Organization Regional Office for Europe. 2014. Jul 01, [2016-02-14]. About health 2020 http://www.euro.who.int/en/health-topics/health-policy/health2020-the-european-policy-for-health-and-well-being/about-health-2020 .

74. World Health Organization. WHO Medical Device Technical Series. Geneva: World Health Organization; 2011. Health technology assessment of medical devices; pp. 
1769. Dinesen. Personalized

https://doi.org/10.30953/tmt.v2.18

Page 37 of 38

$1-92$.

75. European Commission. Communication from the Commission to the European Parliament, the Council, the European Economic and Social Committee and the Committee of the Regions: eHealth Action Plan 2012-2020 - Innovative healthcare for the 21st century. Brussels: European Commission; 2012. Dec 06, [2016-02-14]. http://ec.europa.eu/health/ehealth/docs/com 2012736 en.pdf.

76. Digitaliseringsstyrelsen. 2014. Nov, [2015-12-26]. Initiativer i Strategi for digital velfærd http://www.digst.dk/Digital-velfaerd/Initiativer-og-projekter/Projekter-iStrategi-for-digital-velfaerd .

Author affiliations

1. Laboratory of Assistive Technologies - Telehealth \& Telerehabilitation, SMI, Department of Health Science and Technology, Aalborg University, Aalborg, Denmark

2. Center for Information Technology Research in the Interest of Society (CITRIS), UC Berkeley, Berkeley, CA, United States

3. Faculty of Medicine, Qatar University, Qatar, Qatar

4. Center for Innovative Medical Technologies (CIMT), Odense University Hospital, University of Southern Denmark, Odense, Denmark

5. Connected Health Innovation, Partners HealthCare, Harvard Medical School, Boston, MA, United States

6. Betty Irene Moore Nursing School, Davis Health System, University of California, Sacramento, CA, United States

7. Department of Psychology and Behavioral Sciences, Aarhus University, Aarhus, Denmark

8. Citizens \& Labor Market, Esbjerg Municipality, Esbjerg, Denmark

9. Division of Cardiovascular Medicine, University of California Davis Medical Center, Sacramento, CA, United States

10. Center for Connected Health Policy, Sacramento, CA, United States

11. Department of Public Health Sciences, School of Medicine, University of 
1769. Dinesen. Personalized

https://doi.org/10.30953/tmt.v2.18

Page 38 of 38

California, Sacramento, CA, United States

12. Cleveland Clinic Health System, Cleveland, $\mathrm{OH}$, United States

13. Center for Health and Technology, Davis Health System, UC Berkeley, Sacramento, CA, United States

Corresponding author: Birthe Dinesen, Laboratory of Assistive Technologies -

Telehealth \& Telerehabilitation, SMI, Department of Health Science and Technology, Aalborg University, Fredrik Bajers vej 7, Aalborg, 9220, Denmark, Phone: 45 20515944, Fax: 45981540 08, Email: bid@hst.aau.dk.

This article was originally published in the Journal of Medical Internet Research (http://www.jmir.org), 01.03.2016.

This is an open-access article distributed under the terms of the Creative Commons Attribution License (http://creativecommons.org/licenses/by/2.0/), which permits unrestricted use, distribution, and reproduction in any medium, provided the original work, first published in the Journal of Medical Internet Research, is properly cited. The complete bibliographic information, a link to the original publication on http://www.jmir.org/, as well as this copyright and license information must be included. This article has been cited by other articles in PMC.

Department: Interviews \& Opinions

Tags: telehealth, research, individualized medicine, telemonitoring, prevention, mobile phone 